\title{
Rivera antes de Rivera. Los trabajos pictóricos de Manuel Rivera para el Instituto Nacional de Colonización
}

\author{
Rivera before Rivera. Pictorial Works of Manuel \\ Rivera for the National Colonization Institute
}

MOISÉS BAZÁN DE HUERTA

Universidad de Extremadura. Grupo de Investigación ARPACUR

mbazan@unex.es

Recibido: $29 / 09 / 2015$

Aceptado: 16/01/2016

\begin{abstract}
Resumen
Manuel Rivera (Granada, 1927 - Madrid, 1995), uno de los fundadores y componentes del Grupo El Paso en 1957, es un genuino representante de la vanguardia artística española. Es valorado internacionalmente por sus originales creaciones abstractas con tela metálica. Pero antes de alcanzar esa gran proyección, entre 1952 y 1957 cimentó su carrera en el ámbito de la pintura mural. Trabajó sobre todo para el Instituto Nacional de Colonización (INC), realizando hasta 16 encargos entre murales y cuadros de gran formato. Además de la sede del propio INC, sus pinturas se destinaron a las iglesias de pequeños pueblos rurales en diversas provincias españolas. Esa faceta, mucho menos difundida pero también interesante, centra el presente estudio y supone una aportación notable al conocimiento de la trayectoria del artista y la modernización del arte religioso en el franquismo.
\end{abstract}




\title{
Palabras clave
}

Manuel Rivera; Grupo El Paso; Vanguardia; Arte en el franquismo; Pintura mural; Instituto Nacional de Colonización (INC); Pueblos de colonización.

\begin{abstract}
Manuel Rivera (Granada, 1927 - Madrid, 1995), was one of the founders and members of the Group El Paso in 1957, and he is a genuine representative of the Spanish artistic Avant-Garde. He has been internationally acclaimed for his original abstract works with metal wire. Prior to this, between 1952 and 1957, he built his career in the field of mural painting. He concentrated his work in the National Colonization Institute (INC), performing up to 16 jobs (murals and large-size paintings). In addition to INC main building, he painted several works for local churches in small villages around Spain. This paper is focused on these pieces, much less known than the others despite their interest. This study represents a significant contribution to the knowledge on the artist's career, and on the modernization of religious art in the Franco era.
\end{abstract}

\section{Keywords}

Manuel Rivera; El Paso Group; Avant-Garde. Art in the Franco Era; Mural Painting; National Colonization Institute (INC); New Towns; Colonization Villages.

Referencia normalizada: BAZÁN DE HUERTA, MOISÉS (2016): “Rivera antes de Rivera. Los trabajos pictóricos de Manuel Rivera para el Instituto Nacional de Colonización". Arte y Ciudad. Revista de Investigación, no 9 (abril), págs. 61-90. Madrid. Grupo de Investigación Arte, Arquitectura y Comunicación en la Ciudad Contemporánea, Universidad Complutense de Madrid.

* Este texto ha sido posible gracias a la Ayuda del S.E.C.T.I. (Sistema Extremeño de Ciencia y Tecnología e Innovación) al Grupo de Investigación de la Junta de Extremadura "Arte y Patrimonio Moderno y Contemporáneo (HUM 012)". Se enmarca también junto a otros trabajos en el Proyecto de Investigación La patrimonialización de un territorio: conformación de paisajes culturales entre el Tajo y el Guadiana en Extremadura (HAR 2013-41961-P), auspiciado por el Ministerio de Economía y Competitividad. 
Manuel Rivera Hernández (Granada, 1927 - Madrid, 1995), componente del Grupo El Paso desde su fundación en 1957, es uno de los pilares de la vanguardia artística española. Evidentemente ha pasado a la historia por sus singulares obras abstractas en tela metálica, con las que aportó un nuevo material a la plástica contemporánea, aunando pintura, relieve y escultura en una fórmula única, que renueva el concepto de espacio y produce sugerentes efectos de vibración óptica en la retina del espectador ${ }^{1}$.

La extensa bibliografía y hemerografía publicada sobre el artista se centra casi exclusivamente en su producción con este original medio ${ }^{2}$, y es lógico que así sea, porque es el que le ha otorgado proyección nacional e internacional. Estamos por supuesto entre quienes más aprecian su decisiva contribución, y por eso este artículo resulta tan singular. Nuestra labor es analizar precisamente una faceta del artista mucho menos conocida y muy distinta a sus cruciales aportaciones en el campo de la abstracción, lo cual justifica el título elegido. Nos centramos así en sus encargos para el Instituto Nacional de Colonización entre 1952 y 1957 y asumimos que el período que analizamos no es tan rompedor y relevante, pero su estudio cobra una especial importancia por haber permanecido casi inédito y porque cubre una interesante parcela en el contexto del arte del franquismo durante los años cincuenta.

Sólo en la prensa encontramos algún reflejo de sus trabajos iniciales; ; las publicaciones monográficas tempranas no se ocupan de esta etapa (por ejemplo González, 1959 y Popovici, 1971). Tampoco la gran retrospectiva organizada por el Ministerio de Cultura en 1981, que incluye un primer catálogo razonado (Logroño, 1981). La propia Web Oficial del artista no alude sino de pasada a estas creaciones y de hecho señala su "primera etapa pictórica" a partir de $1956^{4}$.

Es por fin el mismo Rivera quien nos hace conocedores de estos encargos en sus Memorias, publicadas en 2007, donde cita cuatro trabajos, aunque sólo co-

\footnotetext{
${ }^{1}$ Rivera agrupó su consolidada trayectoria en series como Composiciones, Metamorfosis, Espejos, Estelas, Mandalas, Albercas, Mutaciones, Oráculos o Saetas.

${ }^{2}$ Hemos podido localizarla prioritariamente en el Museo Nacional Centro de Arte Reina Sofía y en el Centro Andaluz de Arte Contemporáneo.

${ }^{3}$ Algunas notas aparecen en la prensa granadina a cargo sobre todo de Antonio Aróstegui en el diario Patria, aunque pronto pasará a interesarse sólo por su faceta más avanzada.

${ }^{4}$ Ver http://manuelrivera.net/.
} 
menta dos con cierta extensión (Rivera, 2007). Otro paso para recuperar este período vino con la elaboración en 2009 del Catálogo Razonado del artista a cargo de Alfonso de la Torre y Marisa Rivera, que incluye ya fichas y breves referencias de las obras, aunque buena parte no están reproducidas (De la Torre y Rivera, 2009). Cabe destacar también el catálogo de la exposición De Granada a Nueva York, de 2012, donde Alfonso de la Torre retoma su pormenorizado estudio e incluye la relación de todos los pueblos, si bien sobre el particular no se amplían datos ni se reproducen imágenes (De la Torre, 2012: 91).

Para abordar este artículo, y buscando acceder a la documentación original del artista, utilizada ya por De la Torre, tras contactar con el Centro Andaluz de Arte Contemporáneo y la Galería Leandro Navarro, conectamos con Marisa Rivera, quien nos comunicó que el fondo conservado por la familia se había cedido en 2014 al Museo Nacional Centro de Arte Reina Sofía. Doce archivadores agrupan el legado, aunque sólo los tres primeros afectan a esta etapa, donde hemos podido cotejar recortes de prensa, fotografías, correspondencia y documentación ${ }^{5}$. El resto ha sido trabajo de campo, localizando personalmente las obras que nos ha sido posible o recabando información del resto en parroquias y ayuntamientos.

Veamos por tanto los parámetros en los que se enmarca esta actividad, tanto en la época como en la trayectoria personal del artista. No podemos extendernos en la importante labor acometida por el INC, que durante los años cincuenta y sesenta construyó en España unos 300 pueblos, dentro de un plan general para convertir en regadío amplias zonas rurales infrautilizadas y acogiendo a numerosas familias de colonos. El equipo de arquitectos que afrontó esta iniciativa tuvo la oportunidad de diseñar pueblos ex novo que debían cubrir todo tipo de necesidades, labor que se hizo dentro de unas directrices oficiales, pero gozó también de márgenes para experimentar con soluciones variadas. Las iglesias tuvieron un protagonismo especial, como hito arquitectónico y punto de encuentro, y es en ellas donde se concentran las principales actuaciones artísticas. Para su decoración se utilizaron criterios innovadores, con frecuencia sorprendentes por su modernidad, ya que el arte religioso en la época se movía en modos muy tradicionales. El propio Rivera lo destaca en su discurso de recepción como Académico de San Fernando, donde revisa la evolución de la vanguardia española.

${ }^{5}$ MNCARS. Arch. RIV 1, 2 y 3. CDB. 187199, R. 187421. 
En gran medida esta apertura se debió a José Luis Fernández del Amo (Madrid, 1914-1995) ${ }^{6}$. Reunía para ello la doble condición de arquitecto (responsable de algunos de los pueblos de colonización más valorados, como Vegaviana), con el cargo de director del Museo de Arte Contemporáneo entre 1952 y 1958. Desde esta posición dio un decisivo apoyo a la vanguardia y a los jóvenes que en ese momento estaban iniciando sus trayectorias artísticas más personales. En sus Memorias Rivera alude repetidamente a su importante papel y su contacto fue muy estrecho. El arquitecto adquirió obras suyas para el Museo, defendió que se le otorgara una medalla en la Exposición Nacional de 1952, le animó a trasladarse a Madrid para afianzar su carrera y le facilitó diversos encargos 7 .

En ese contexto Rivera va cimentando su labor en la pintura mural, que se inicia con la decoración del Teatro Isabel la Católica en Granada en 1951 y tiene un punto de inflexión un año después en la Capilla del Pantano de Cubillas, donde abre la línea que seguirá en sus primeros trabajos para el INC. Había tenido formación artística en la Escuela de Artes y Oficios de Granada y Bellas Artes de Sevilla, pero la propia experiencia sería su mejor vía de aprendizaje, y no le faltarán oportunidades. Con el tiempo la prensa de la época lo calificaría como uno de los mejores muralistas españoles, pero su producción no surge aislada, sino en un momento de auge. Bajo la ascendencia de Daniel Vázquez Díaz, discípulos directos como Carlos Pascual de Lara y artistas como Valdivieso, Hernández Carpe, Ortega, Padrós, Farreras, Suárez, Vaquero Turcios, el matrimonio Lozano-Bartolozzi o el extremeño Pérez Muñoz, entre otros, renovarían este campo en edificios civiles y sobre todo religiosos (Montoya, 2005).

Rivera asumió esta etapa con buenas perspectivas, porque le permitía una salida profesional, el diálogo con la arquitectura, cierto grado de experimentación y "hacer un arte para la masa". Su estilo introduce una patente geometrización compositiva, al subdividir el espacio con líneas y campos de color, pero sin llegar a romper con el lenguaje figurativo, algo que en las iglesias de Colo-

\footnotetext{
6 "Un arquitecto para el arte contemporáneo", en palabras de Miguel Centellas, quien ha estudiado en su tesis su aportación al INC. Ver Centellas, 2007 y 2010; y también Cordero, 2014.

${ }^{7}$ Llamativa es incluso la similitud entre las telas metálicas de Rivera y el diseño interior que hace Fernández del Amo para el Presbiterio de la iglesia de El Realengo (Almería).
} 
nización parece sólo reservado a las vidrieras. Sus obras resultan novedosas para la época y en ellas percibimos estilemas en fisonomías, gestos y posturas, que iremos desgranando al analizar cada ejemplo. El recorrido nos servirá también para valorar cómo se conserva este sugerente conjunto de obras.

El que abre la serie, y uno de los más espectaculares, es el gran mural para el presbiterio de la iglesia de Foncastín, Valladolid (Fig. 1), que acomete entre 1952 y 1953. En este caso el propio Rivera describe las circunstancias del trabajo en sus Memorias:

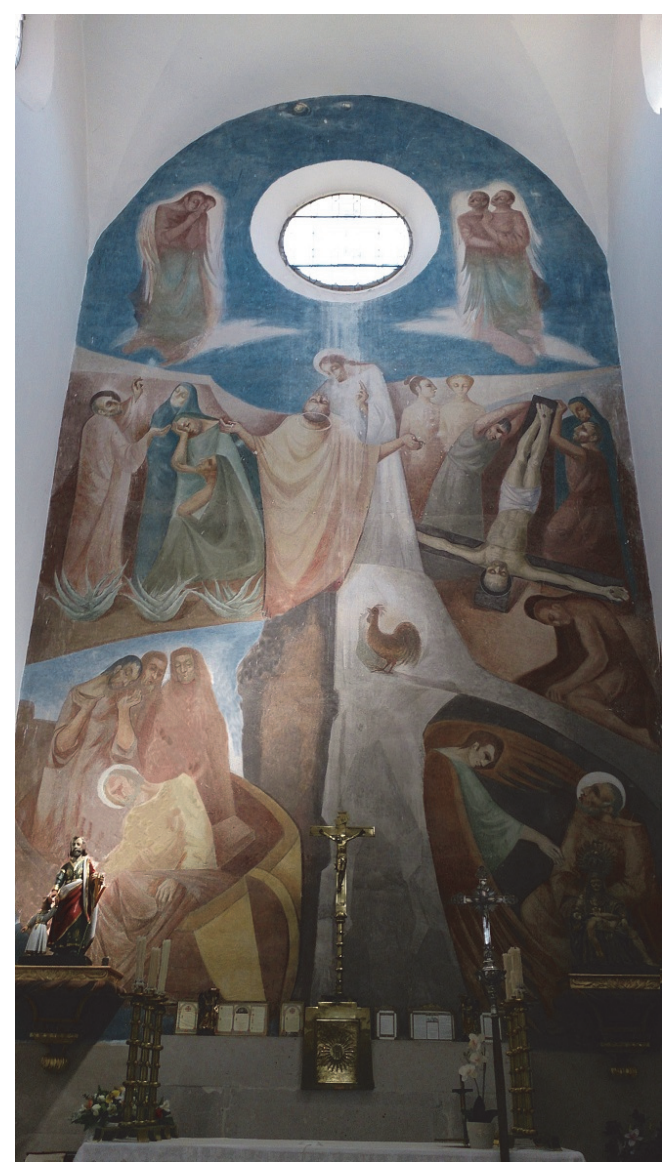

Fig. 1. Iglesia de Foncastín (Valladolid)

Un día Fernández del Amo me habló de un encargo, un mural de $40 \mathrm{~m}^{2}$ para una iglesia del INC en el pueblo de Foncastín y cuyo arquitecto era Ayuso. Fui al Instituto, Fernández del Amo me presentó a este arquitecto y a don José Tamés, jefe de servicio de arquitectura, me recibieron muy bien y me dieron los planos de la iglesia para realizar el boceto, con el tema de la vida de San Pedro. José Luis me dijo que trabajase con entera libertad y enseguida me puse a trabajar y al terminar el año, el boceto de la iglesia estaba acabado, y cuatro o cinco cuadros muy estilizados y que empezaban a estar cerca de la abstracción (Rivera, 2007: 73) ${ }^{8}$.

Del relato se infiere la estrecha colaboración entre artista y arquitecto, aunque se deja al primero trabajar con libertad estilística una vez asignado el espacio. Sin embargo, el acercamiento a la abstracción al que alude no va referido al encargo de la iglesia, sino a lienzos independientes, de la serie Albaicín. Con todo, la obra

${ }^{8}$ Agradecemos a Dolores Mayo, alcaldesa de Rueda y previamente de Foncastín, la fotografía de la obra. 
mural resulta de lo más innovadora, pues somete el espacio a una compleja geometría, articulando diversos episodios como si fueran viñetas y en una línea próxima al citado mural granadino del Pantano de Cubillas. Rivera continúa comentando las peculiares circunstancias en que se realizó y las reservas por parte de las autoridades eclesiásticas:

A principios del año (1953) entregué el boceto al Instituto de Colonización; a todos les parecía muy bien y sólo faltaba la aprobación del arzobispo de Valladolid, para trasladarme al pueblo y comenzar el trabajo; pero los días comenzaron a pasar y no se recibían noticias del arzobispado, nuestro dinero se iba acabando y empezamos a sentirnos muy inquietos.

Mientras llegaban noticias de Colonización, continuaba con ensayos de cuadros en la pensión y un día me llamaron del Instituto para decirme que al arzobispo de Valladolid le había parecido demasiado vanguardista mi boceto para la iglesia del pueblo y que no daba su consentimiento. Quedé desolado y Fernández del Amo me aconsejó que me marchase a Valladolid y que hablase yo personalmente con el arzobispo, para ver si podía convencerle. (...)

Llegamos una tarde a Valladolid y nos alojamos al lado de la estación en una sórdida pensión e inmediatamente pedí una audiencia con el arzobispo. Este me recibió a la mañana siguiente y me dijo que el boceto no lo entendía y que le hiciese una ampliación de un detalle del mural. Enseguida compré papel, colores, etc. y en la pensión, mientras Mary reposaba, me puse a pintar un detalle del boceto, creo que una cabeza de San Pedro. Al día siguiente y con la pintura bajo el brazo, solicité de nuevo ver al arzobispo. Le convenció la ampliación y me autorizó a que comenzase las pinturas de la iglesia, advirtiéndome que al mediar éstas, le avisase para que él enviase al Consejo Diocesano y diera el consentimiento para continuarlas. Menos mal que el arzobispo falleció poco después y no hubo necesidad de este requisito.

Inmediatamente nos marchamos al pueblo de Foncastín, cerca de Illescas. Era un pueblo triste en medio de la llanura castellana y que nos deprimió en principio; estaba habitado por colonos asturiano-leoneses, callados y hoscos, y nos dieron para habitar la casa del cura al lado de la iglesia, puesto que éste todavía no estaba nombrado. Arreglamos la casa, hicimos algunas compras de víveres y al día siguiente una mujer del pueblo nos regaló unos chorizos, otra una cabeza seca de cerdo, alguien más judías, es decir, que empezamos a rehacernos de las hambres pasadas y con el cambio de aires, Mary recuperó el bienestar y desaparecieron las molestias del embarazo. Yo empecé a pintar enseguida en la iglesia y los días comenzaron a pasar placenteramente. Los sábados nos envia- 
ban un coche del Instituto de Colonización para pasar el domingo en Valladolid y descansar del pueblo. Valladolid nos pareció aburrido y cuando vimos las pocas películas que ponían, nuestra única diversión era visitar las librerías de viejo y comprar libros. Vivíamos la noche del sábado y el domingo en una pensión de la Plaza Mayor. Llegábamos a esta pensión el sábado por la noche y con sólo un maletín y como después de cenar apenas había diversión, nos encerrábamos a leer en la habitación. (...)

La pintura mural que realizaba en Foncastín era de cuarenta metros cuadrados, el trabajo mucho y los días pasaban. Empezamos a sentir claustrofobia en aquel pueblo y las últimas semanas fueron pesadas. Al final acabé el trabajo y con gran alegría regresamos a Madrid; cobré unas 30.000 pesetas del Instituto de Colonización y al final de la primavera regresamos a Granada a descansar y a esperar a que Mary diese a luz en nuestra tierra (Rivera, 2007: 73-76).

En otra fuente Rivera aún concreta aún más la anécdota con el obispo, ya que éste pensaba que en el mural los santos no llevarían ojos, y a pesar de explicarle que se trataba sólo de un boceto, tuvo que dibujárselo en detalle. Comenta además que el control de la obra durante su realización fue exhaustivo y cabe suponer que trabajaría bajo el temor de una paralización (Antolín, 1983).

Rivera parecía querer exprimir el tema y desplegó una obra copiosa en contenidos. Iconográficamente, la primera escena muestra a Pedro como pescador en Betsaida de Galilea, tirando las redes desde la barca junto a sus compañeros. Arriba desempeña su labor de apostolado, predicando ante un grupo de fieles con diferentes actitudes. En la zona inferior encontramos la liberación de San Pedro por el ángel, dirigiendo hacia él la mano para soltar sus cadenas y guiarlo (Hechos de los Apóstoles, 12, 1-11). La presencia del gallo alude a la triple negación de Cristo antes de que se produjera su canto, elemento al que se otorga importancia ya que formalmente centra la composición. Finaliza el ciclo el martirio de San Pedro en la cruz, ante personajes con gestos resignados o dolientes; Pedro, sintiéndose indigno de ser crucificado como su Maestro, pidió ser clavado cabeza abajo y así lo refleja la escena, cuyo modelo más próximo encontramos en el fresco de Filippino Lippi en la Capilla Brancacci de Florencia. Esta influencia de la pintura quattrocentista puede rastrearse también en el tratamiento pétreo y espacial, que recuerda a las Escenas de los Santos Eremitas o San Jorge y el dragón de Paolo Uccello. El mural de Rivera culmina en sentido ascensional con Cristo recibiendo y bendiciendo a San Pedro, antes de otorgarle las llaves y subir a los cielos, donde 
dos parejas de ángeles parecen esperarlo. Un óculo centra este espacio superior, iluminando la escena, pero también ha sido origen de filtraciones de agua que han perjudicado la conservación del mural, junto a piquetes y pequeñas pérdidas que aconsejan una pronta restauración. (Fig. 2)

Un segundo mural consigna Rivera en sus Memorias. En el invierno de 1953 realiza los bocetos para la iglesia de Águeda del Caudillo, aunque sólo lo cita como un pueblo próximo a Ciudad Rodrigo. La ejecución se llevó a cabo en la primavera de 1954 y se desplazó al pueblo mientras su mujer y su hija permanecían en Granada. Contó con la colaboración de García Calvo, pintor al que conoció en Madrid y que llevó con él para agilizar el trabajo, porque su prioridad era trasladarse cuanto antes a la capital española (Rivera, 2007: 79-80).

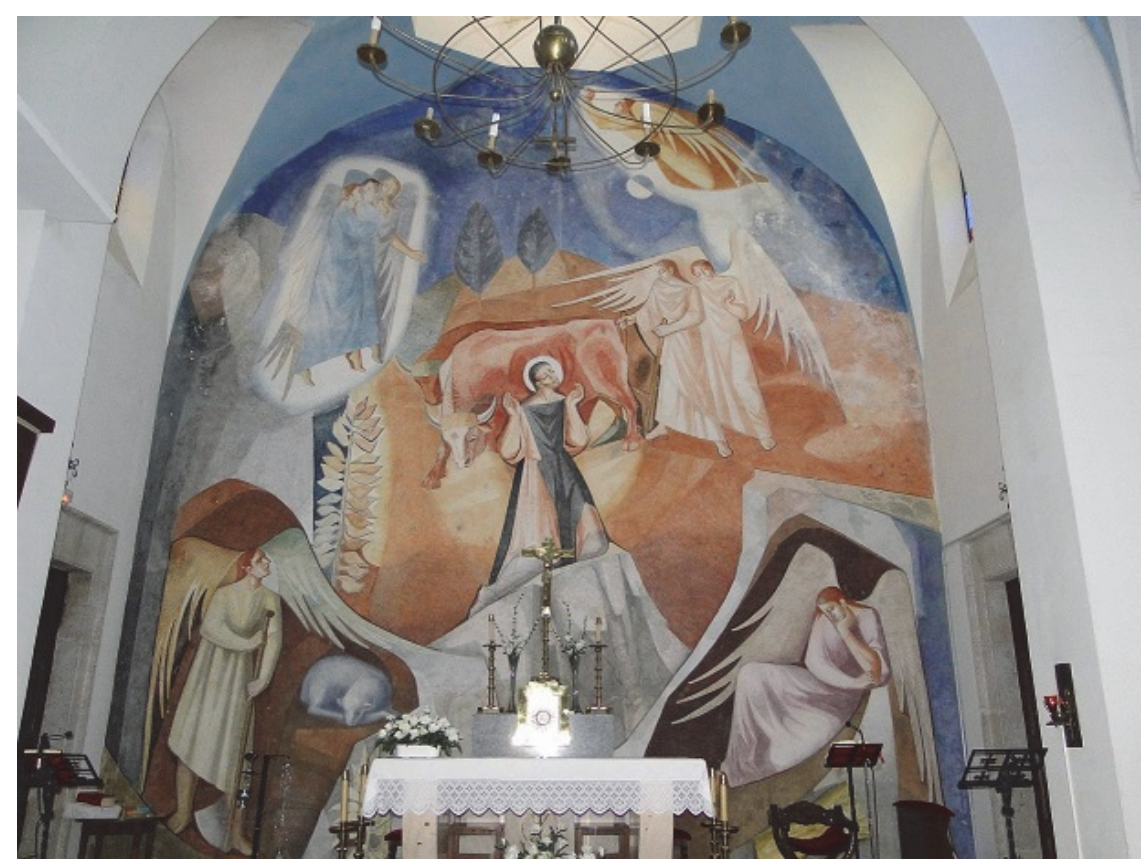

Fig. 2. Iglesia de Águeda del Caudillo (Ciudad Rodrigo, Salamanca).

Representa a San Isidro Labrador, devoción habitual en los pueblos de colonización al estar directamente vinculada con la agricultura. Narra el milagro por el que los ángeles asumen sus labores en el campo mientras éste permanece rezando. Por ello un ángel sostiene una azada y otros dirigen el arado con la yunta de bueyes. Rivera resuelve la escena con una valiente alternancia de zo- 
nas de color, con el marrón dominando en dos tercios y el azul en el cielo, donde los ángeles vuelan envueltos en luz. A su vez, los dos inferiores contribuyen con sus alas a delimitar sendas zonas rocosas de ascendencia uccelliana, una de perfil anguloso y otra más ondulada que marca una transición fluida hacia el gris del promontorio central sobre el que se arrodilla el santo.

El mural, de nuevo con un gran formato, está firmado por el artista. Nos indica el párroco que hasta mediados de los años noventa no se realizó el traslado de propiedad al Obispado, y fue entonces cuando se hicieron algunas labores de conservación por un artista local. Algunas manchas parecen revelar nuevos problemas de humedad, aunque desde la iglesia se considera que se encuentra en razonable buen estado (Muñoz, 2008)9.

Un tercer mural para iglesias de colonización es el de Cilanco (Albacete), que en su autobiografía manuscrita Rivera sitúa en $1954^{10}$. Aunque el tema de la Asunción de la Virgen lo veremos en diversas obras, esta versión es singular por el protagonismo de las líneas curvas que subdividen la escena y separan a los asistentes en dos grupos, enmarcados por masas de color. Sólo dos ángeles acompañan a la Virgen en su tránsito a los cielos, y destacan por su originalidad detalles como la fusión de tres cabezas que muestra el conjunto de la izquierda. (Fig. 3).

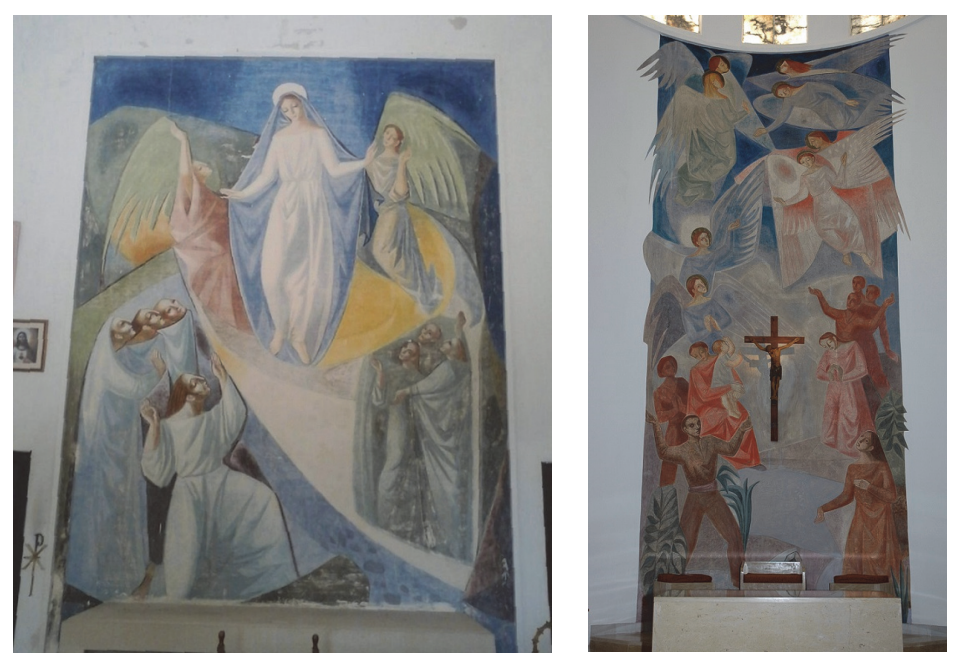

Figs. 3 y 4. Iglesias de Cilanco (Albacete) y Benagéber (Valencia).

${ }^{9}$ Agradecemos a Esther Abujeta Martín y Santos Vicente las fotografías de la obra.

${ }^{10}$ MNCARS. Arch. RIV 1, 1-2. 
Entre 1954 y 1955 aborda Rivera un nuevo encargo mural para la parroquia de San Antonio Abad de Benagéber (Valencia). Su formato es más vertical que el de Cilanco y ostenta un mayor número de figuras, pero la iconografía angélica, el tratamiento del espacio y la gama cromática siguen parámetros análogos. Hay un plano terrenal con elementos naturales y campesinos que rezan o alzan sus brazos hacia el cielo, donde se despliegan por parejas ocho ángeles en diversas posturas, todo en agradables tonos pastel. (Fig. 4).

El mural fue objeto de una minuciosa restauración en 1992 llevada a cabo por la Universidad Politécnica de Valencia y recogida en un pequeño libro (VV. AA., 1992) ${ }^{11}$. En concreto se debe a un amplio equipo (hasta 37 personas, en su mayoría alumnos de último curso) coordinados desde el Departamento de Conservación y Restauración por Carmen Pérez García y Pilar Roig Picazo. Una introducción del párroco de la iglesia, Alberto Caballer Caballer, sitúa la historia del pueblo, la iglesia y su mural, para exponerse luego la memoria del proceso restaurador, si bien apenas se tocan cuestiones iconográficas y los responsables desconocen la autoría de la obra ${ }^{12}$.

Nos detendremos en algunos de estos aspectos porque las informaciones técnicas sobre este trabajo, con matices, son extrapolables al resto de los murales del artista. Ocupa una superficie cóncava de 7 x 3,20 m. El soporte es el tapial valenciano, con una primera hilera de ladrillo recubierto de una capa de argamasa y piedras, sobre la que se aplica un enlucido y la propia pintura. La técnica es al temple, utilizando la caseína como aglutinante, aunque la escasa cantidad aplicada al pigmento generó ciertos problemas de adherencia y pulverulencia. Las filtraciones de agua desde las ventanas superiores habían ocasionado algunos daños, pero fueron más graves las sulfataciones de la zona inferior, generadas por capilaridad debido a un mal drenaje de la parte posterior de la iglesia. También se produjeron grietas, incisiones por colocación de andamios y manchas blancas al repintarse la iglesia sin proteger la pared.

Pero hubo otras dos circunstancias: la incrustación en época no fundacional de un sagrario en el centro del mismo, abriendo un hueco en la pared (al-

\footnotetext{
${ }^{11}$ Agradecemos su envío a Alberto Caballer.

${ }^{12}$ Lo más llamativo es que la firma incisa con mayúsculas de RIVERA es tomada como "vandalismo de incisión gráfica", pensando que se trata de un añadido cuando es en realidad la rúbrica del autor, conservada bajo un repinte.
} 
go insólito que refleja el poco valor otorgado a este patrimonio, aunque con posterioridad sería retirado y tapiado); y separar el altar del muro para adaptarse a las normas litúrgicas derivadas del Concilio Vaticano II. Ambas actuaciones trajeron consigo un nuevo estucado en zonas clave, con toscos repintes y alteraciones que la restauración ha conseguido paliar.

Tras ese proceso se decidió sustituir a San Antonio por un crucificado que centrara las miradas de ángeles y fieles, y así lo revela la fotografía que incluimos. Pero se buscaba una presencia más notable, y en 2012 se encarga al escultor Ricardo Rica Tormo un crucificado glorioso o triunfante para presidir el mural. La talla, de gran formato $(2,30 \mathrm{~m}$.) y en madera de ciprés, es obra de calidad, pero por sus dimensiones y las sombras añadidas que proyectan los focos, resta desde 2013 bastante protagonismo al mural de Rivera ${ }^{13}$.

Tras Foncastín y Águeda, otro de los cuatro encargos vinculados al INC que Rivera consigna en sus Memorias es el que precisamos ahora. Señala que en 1954:

Comencé un cuadro con el tema de la Adoración de los Reyes y otro con un San Humberto, ambos encargos de Fernández del Amo para la capilla de una finca del Instituto de Colonización en Santa Cruz de Mudela. Cuando terminé ambas obras nos fuimos a Mudela a montarlas en la capilla y gustaron lo suficiente para crearme un clima muy bueno en el Instituto de Colonización (Rivera, 2007: 80).

De ambas obras sólo hemos localizado conservada la primera, firmada en mayúsculas con su nombre completo, que reproducimos gracias a una fotografía de Miguel Centellas. Su enclave es una construcción utilizada como pabellón de caza y rehabilitada con otros fines. Se trata de un cuadro de gran formato y no de una pintura mural, aunque su tratamiento formal sea similar. Rivera agrupa las figuras en un espacio exiguo. La Sagrada Familia se enmarca ante unas arquitecturas apenas insinuadas, y un recurso inteligente es el aumento progresivo de la luminosidad en la figura del Niño Jesús. En el lado derecho se disponen los tres Reyes Magos junto a sus pajes; van montados a caballo, aunque sólo uno de los animales se muestra casi completo de perfil, mientras de los otros sólo vemos las cabezas. Los presentes: oro, incienso y mirra, se sitúan a los pies de la Familia en recipientes de concepción cubista, muy originales en su planteamiento. En realidad la compartimentación afecta a todo el cuadro y se

${ }^{13} \mathrm{El}$ proceso se describe con pormenor en http://parroquiasanantonioabad-sab.org/historia-delcristo-del-altar/. Consultado el 1 de septiembre de 2015. 
hace más evidente en los pliegues de las vestiduras y los aperos del caballo. Peculiares son las fisonomías de la Virgen y San José, de cierto recuerdo picassiano en su tez lánguida, con hombros rectos, cuello horizontal y cabeza inclinada, en diálogo formal con el paje oferente que centra la composición. La frialdad del azul nocturno contrasta con las gamas cromáticas del primer término y el resultado es muy colorista, más que en otros ejemplos de la época ${ }^{14}$ (Fig. 5).

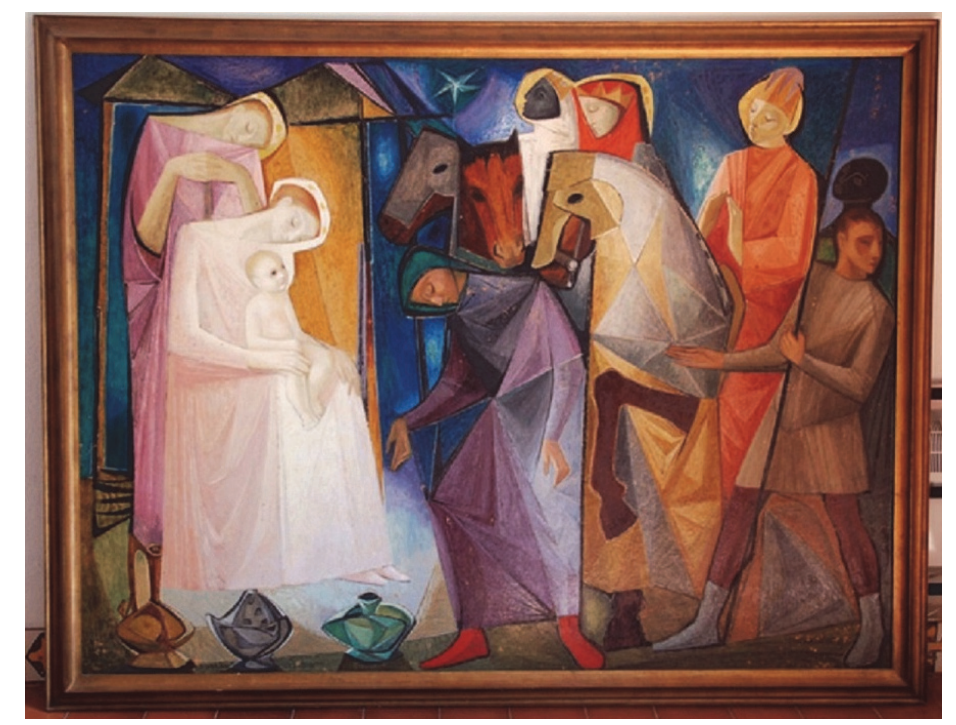

Fig. 5. Capilla de Santa Cruz de Mudela (Ciudad Real).

Otro cuadro de gran formato, representando en este caso a la Virgen con el Niño, completa estas alternativas a la pintura mural. El INC lo encargó para el núcleo de Doñana (el nombre proviene del antiguo cortijo de Doña Ana) en Cártama (Málaga). En el catálogo razonado del artista se ubica por error la obra en Santa Ana de Cártama y 1957, y se añade la ficha de una Virgen con el Niño en Doñana (Huelva) que en realidad va referida al cuadro que nos ocupa ${ }^{15}$. Fue pintado en 1955 y firmado “M. Rivera” con las letras del apellido en minúsculas.

\footnotetext{
${ }^{14}$ El cuadro fue expuesto, como signo de las nuevas corrientes, en las muestras Continuidad del Arte Sacro del Ateneo de Madrid y la Gran Exposición de Arte Sacro de Zaragoza en 1958. Ver Ureña, 1982: 153-155.

${ }^{15}$ En el Archivo del artista figura la orden de pago por importe de 8.000 pesetas, realizada desde el INC por encargo de José García Nieto y fechada en Granada el 10 de mayo de 1955. MNCARS. Arch. RIV 3, 1-10. Agradecemos a José Manuel Trujillo, del Ayuntamiento de Cártama, la fotografía del cuadro.
} 
La geometría domina de nuevo la composición, dividida por planos lineales y de color. El asiento se dispone inclinado e inestable sobre un suelo fragmentado, de manera que la Virgen apoya tan solo la punta de sus pies. El resto parece aludir a elementos vegetales, apenas sugeridos y que adquieren un tinte casi surrealista en su cualidad fluorescente. Hay que destacar la valentía

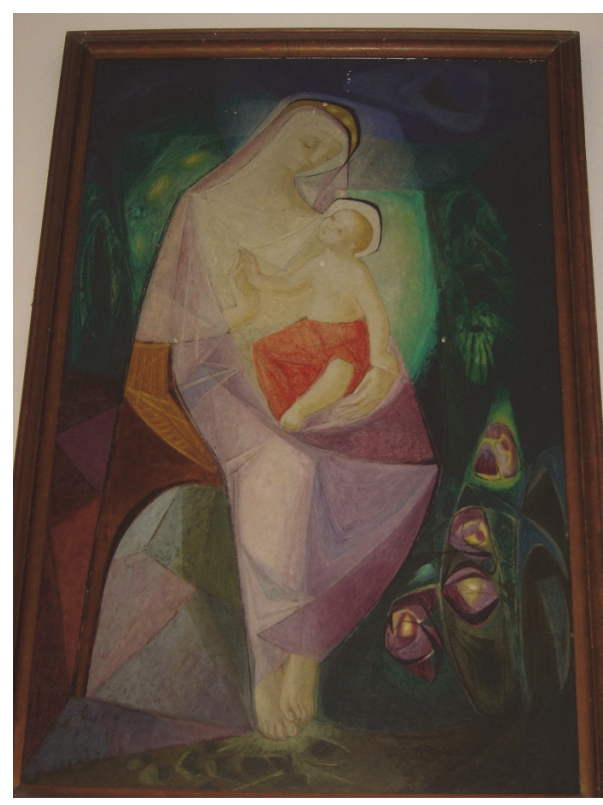

Fig. 6. Iglesia de Doñana, Cártama (Málaga) cromática de Rivera, con esa gama violácea y esos verdes intensos, nada habituales en otras propuestas. Las dos figuras participan de la misma voluntad geométrica, al menos en su atuendo, de manera que los pliegues y sus ángulos marcan diversos ejes direccionales en un sutil juego de zigzag. Aquí, Madre e Hijo se comunican visualmente y unen sus manos en un gesto más próximo que en la actitud oferente de Mudela. (Fig. 6)

Rompemos la temática religiosa al analizar ahora una obra de carácter civil, relevante además porque supuso actuar en la propia Sede del INC en Madrid, y de nuevo gracias a Fernández del Amo, quien puso al artista en contacto con el arquitecto José Tamés. En el edificio intervinieron también otros artistas, como Ángel Carretero, Antonio Cano Correa, Amadeo Gabino y Ángel Ferrant. La importancia del encargo conlleva que, como en Foncastín, Rivera se explaye en el relato del proceso:

El nuevo edificio del Instituto de Colonización en la Castellana se estaba terminando y Fernández del Amo habló con el director de arquitectos y autor del proyecto, don José Tamés, sobre la posibilidad de unas pinturas murales en la escalera de subida a la dirección general y que fuese yo el artista que las pintase. Tamés no recibió mal la idea y me mandó llamar para hablar del asunto y para que le hiciese algunos esquemas primarios. Aunque el encargo no era en firme, yo me volví loco de alegría. Ya no eran las iglesias de los pueblos que hacía ya sin ilusión ante los problemas de obispados, etc., era una obra muy importante en Madrid y con bastante libertad. (...) 
Yo me puse a trabajar como loco, haciendo bocetos en cartones, y cada vez que llevaba un proyecto al director, me hacían cambiar alguna cosa, nuevos bocetos, nuevas discusiones y nuevos cambios, pero el encargo se afianzaba. Por fin, me aprobaron bocetos definitivos, empezó la discusión de la técnica y decidí pintar al óleo sobre la piedra de Colmenar que recubría la escalera. Realicé una ampliación del boceto en una placa de esta piedra en el estudio que Carretero tenía entonces en el edificio de los Nuevos Ministerios y presentada en el Instituto se formalizó el encargo.

Empecé las pinturas con una gran alegría y vitalidad; eran cuatro grandes paramentos en la escalera y no tuve tropiezos; técnicamente no hubo problemas y, como concepto, correspondía a lo que entonces hacía yo en el campo figurativo. Naturalmente no me dejaron hacer una obra de más problemas, pero yo estaba contento y apenas me sentí atado. La obra era importante y yo también empecé a sentirme importante, de otro lado el contrato era por un total de unas 100.000 pesetas, entonces mucho dinero para mí. La obra se acabó, quedé contento y se creó un buen clima en torno a mí (Rivera, 2007: 82-83). (Fig. 7)
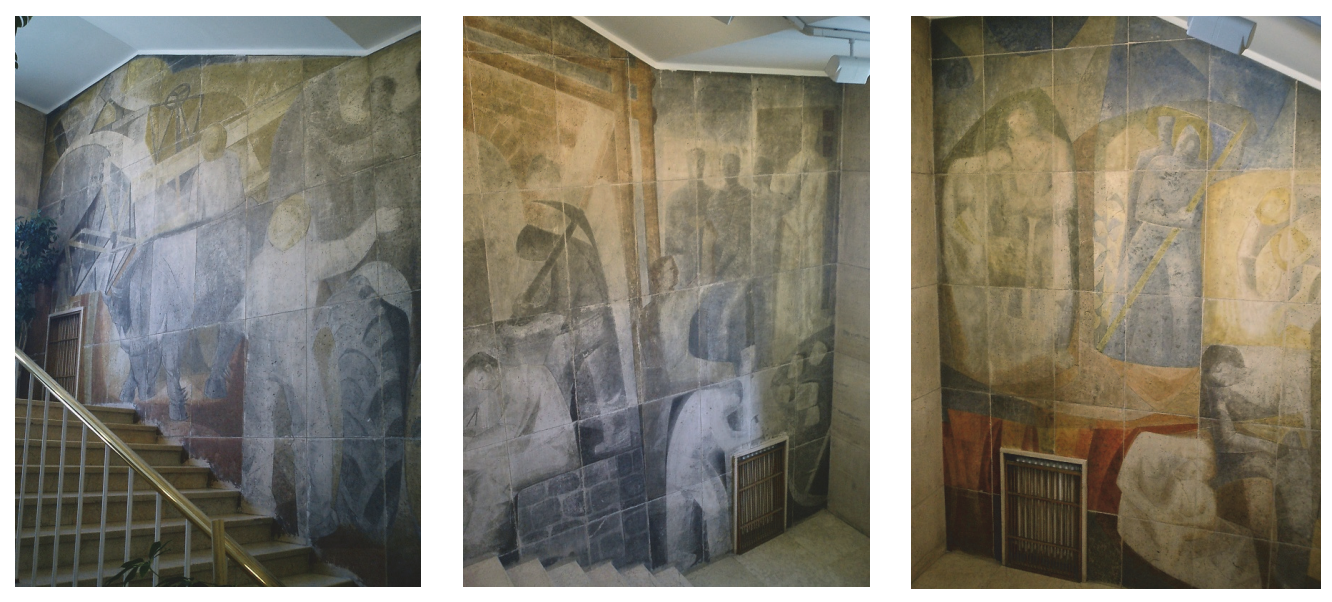

Fig. 7. Mural en la escalera de la sede del INC en Madrid.

La información del artista es reveladora porque abarca todo tipo de cuestiones. Pero cabe complementarla además con el contrato de la obra, archivado en su documentación, aunque la cifra estipulada en el mismo es de 80.000 pesetas, cobrada en tres plazos entre abril y diciembre de 1955. La intervención de Rivera se desplegó en varios tramos sucesivos, cuyos temas, figurativos y alegóricos, aparecen reflejados en el contrato y debían representar "los 
fines y misión social del Instituto, tanto en la transformación del campo como la elevación material y moral del pueblo campesino" 16 .

Suponemos que para Rivera sería un alivio alejarse, al menos temporalmente, de los temas religiosos. Encontramos así labradores (hombres y mujeres en familia, con azadas o recolectando gavillas) que comparten su trabajo con bueyes, caballos, tractores y maquinaria; las más variadas labores de construcción; y guiños significativos, como el arquitecto que con un compás diseña los planos de un pueblo, un cantero cincelando y, cómo no, un pintor dibujando un mural. Los paramentos se fraccionan en bloques de piedra cuyas uniones se dejan a la vista, pero a ellas superpone Rivera su propia composición, con arquitecturas y espacios curvos que aíslan las figuras o grupos. Hay que sumar la dificultad de adaptarse a un complejo marco inclinado, pero el encargo se resuelve con maestría y el artista lo firma orgulloso (Tamés, 1956).

Esta línea de trabajo tendría continuidad en 1956, con planteamientos análogos, en la pintura mural y vidriera con elementos vegetales de la Sala del Cultivo del Tabaco para la Escuela de Ingenieros Agrónomos situada en la Ciudad Universitaria de Madrid, también por encargo del INC. Aquí combina dos técnicas y en la pintura además diversos recursos, tanto en la peculiar disposición por zonas de los personajes que recogen el producto, como en la inclusión de una figura alegórica femenina, con trazo lineal blanco sobre un evanescente fondo oscuro. Sigue también esta estética en los murales para los comedores de la Universidad Popular de Córdoba, un descomunal encargo que le tendría ocupado a fines de 1956 y principios de 1957.

Pero queremos aludir a otra faceta menos conocida y no reseñada en su curriculum: una colaboración más con el INC al diseñar la portada y parte de las ilustraciones de la revista Vida Nueva, el medio por el que el Instituto se comunicaba con los colonos. El primer número se edita en marzo de 1956, y el dibujo de Rivera ocupa tanto el frente como la parte posterior. En él podemos reconocer la iconografía conocida de campesinos y animales junto a un tractor; todo ello con un trazo abocetado, cuya peculiaridad es la inclusión aleatoria de fondos coloreados, que además cambian en los sucesivos números ${ }^{17}$. (Fig. 8)

\footnotetext{
${ }^{16}$ MNCARS. Arch. RIV 3, 1-5. Agradecemos las fotografías a Rafael Fernández del Amo.

${ }^{17}$ Lo dábamos a conocer en: Bazán y Centellas, 2012: 404-405.
} 
Fig. 8. Portada de la revista Vida Nueva.

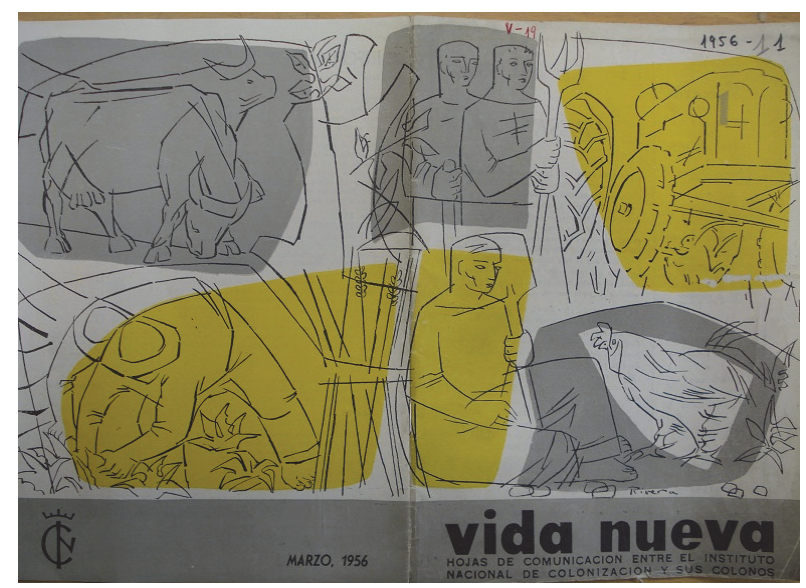

Tras este interludio de temática profana, volvemos a la pintura religiosa con dos nuevos murales para iglesias del INC. En sus apuntes manuscritos Rivera sitúa una iglesia en la provincia de Cádiz en $1956^{18}$, y se refiere sin duda a la de Majarromaque-José Antonio, junto a Jerez de la Frontera. La superficie muestra hoy bastantes roces y pérdida de la imprimación, por lo que sus colores son más tenues que los inicialmente empleados y precisaría una intervención. Sigue pautas compositivas habituales, con una disposición concéntrica y dos planos en altura. Cabe comentar en este caso la mayor presencia de elementos naturales. En la actualidad el eje del presbiterio lo ocupa un crucificado, que sustituye la imagen de María (Virgen del Pilar) que presidía la obra original y a la que se dirigían las miradas de los protagonistas. Hay pues una alteración del mensaje iconográfico, por cuanto lo sugerido por Rivera es una aparición mariana, justificativa de las actitudes devocionales de los campesinos ${ }^{19}$. (Fig. 9)

Cierra este bloque, entre 1956 y 1957, otra pintura mural con el tema de la Asunción de María, realizada en este caso para la iglesia de Alberche del Caudillo (Toledo). Su identificación podría ofrecer algunas dudas, por cuanto hay fuentes que atribuyen su autoría a la pintora Justa Pagés ${ }^{20}$. Pero su esti-

\footnotetext{
${ }^{18}$ MNCARS. Arch. RIV 1, 1-2. El Ayuntamiento de Jerez nos ha facilitado la imagen reproducida.

${ }^{19}$ Una escena similar, con la Virgen y el Niño sobre una columna, rodeada por cuatro ángeles, se reproduce en un mural cerámico exterior firmado por Arcadio Blasco.

${ }^{20}$ Lo señala muy a posteriori y con dudas previas, el arquitecto Manuel Jiménez Varea en carta al alcalde de Alberche el 29 de noviembre de 1991. Lo recoge en su documentado trabajo Cardona, 2006: 409. Y, aunque con errores, parecía sugerirlo el restaurador de la obra junto a su firma.
} 
lo no cuadra dentro de la trayectoria mucho más realista y tradicional de Pagés, y un análisis detenido refleja notas de estilo propias de Rivera en el tratamiento y punteado de las alas, los rostros de perfil y los nimbos; además se cita en la entrevista de Enriqueta Antolín, confirmándolo el escultor José Luis Sánchez; y el mismo Rivera incluye en su autobiografía un mural para la provincia de Toledo, recogiéndose también en su catálogo razonado.

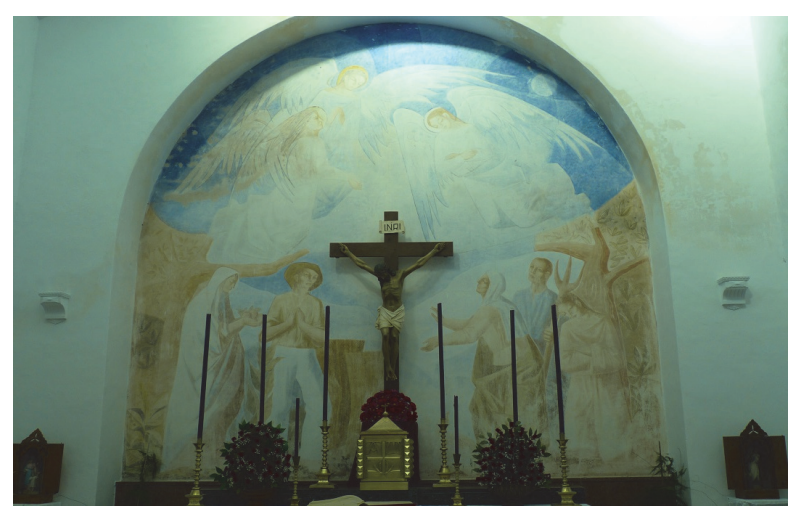

Fig. 9. Iglesia de MajarromaqueJosé Antonio, Jerez de la Frontera (Cádiz).

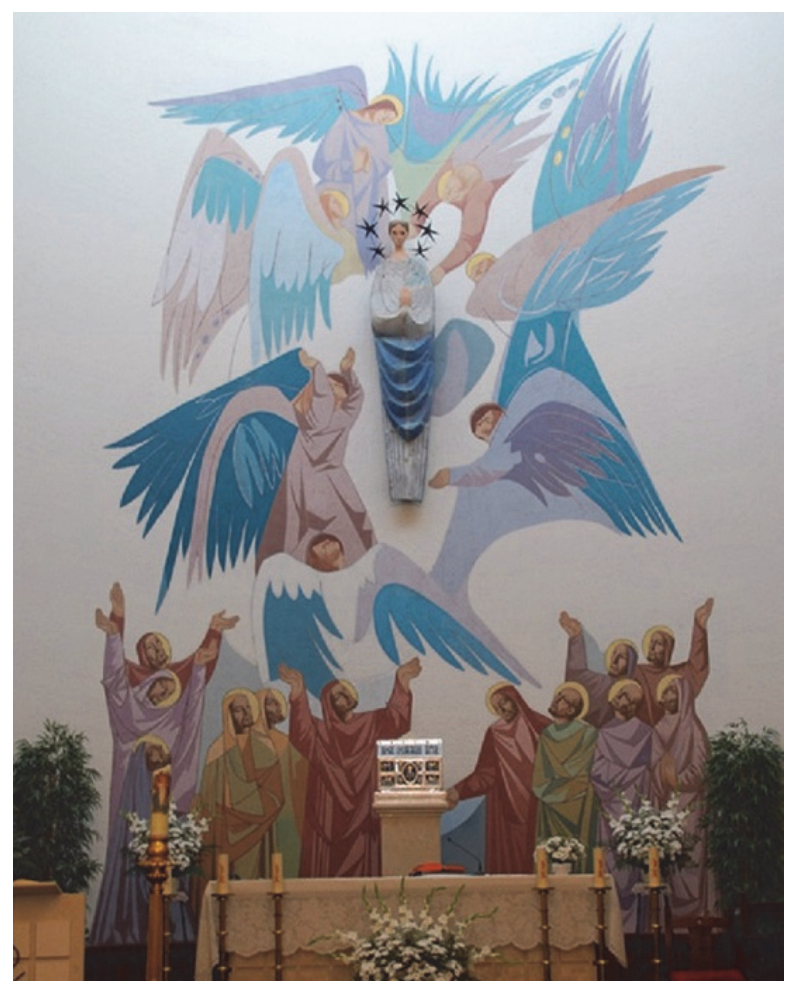

Fig. 10. Iglesia de Alberche del Caudillo (Toledo). 
El mural fue restaurado en 1996 por Miguel Ángel Rego Cortés, y una fotografía antigua revela que su intervención no alteró demasiado la forma original, aunque no nos permite apreciar si lo hizo con el sombreado. Por eso sorprende que la obra carezca de ambientación paisajística, recortándose ante el fondo blanco las figuras de los doce apóstoles y el amplio grupo de ángeles $^{21}$. Las alas muestran aquí menos volumen de lo habitual, resultando más planas, aunque extraordinariamente dinámicas; sí mantiene Rivera los pliegues angulosos y geométricos en las túnicas del apostolado bien equilibradas en su gama cromática. (Fig. 10)

Visto hasta ahora el panorama, se detecta una gran dispersión en los encargos de Rivera para el INC, pero es que hemos optado por agrupar en un solo bloque el núcleo más importante de sus intervenciones. Es en Extremadura, en concreto en la provincia de Badajoz, donde encontramos hasta cinco obras, circunscritas al ámbito religioso, y comprendidas entre 1953 y 1957. De las cinco, sólo una aparece fotografiada y fichada de forma individualizada en el catálogo razonado; las otras cuatro se citan en un bloque de "otros trabajos" sin ficha propia y con data aproximada, de ahí que nuestra aportación complete la principal de las lagunas en este periodo. De hecho, el peso del INC en Extremadura fue muy importante. 20 pueblos se construyeron en torno a la cuenca del Tajo y sus afluentes, sobre todo en los Valles del Alagón y el Tiétar; y otros 38 en las Vegas Altas y Bajas del Guadiana, a los que se suman cuatro más aislados al sur de la provincia de Badajoz. La pintura mural exige obviamente la presencia del artista, y se recuerda en concreto en Pueblonuevo del Guadiana. En los casos de cuadros sobre lienzo o tabla no es del todo necesaria y no nos consta si el autor se desplazó físicamente a la zona.

Una situación peculiar se da en las noticias sobre la iglesia de Ruecas. En las fichas del Instituto Nacional de Colonización se indica para esta iglesia la realización de, nada menos, 24 lienzos sobre la vida de Santa Teresa. Un error de transcripción, sin duda, porque en el contexto de la época y los proyectos artísticos del INC no tiene sentido un encargo de tal magnitud ${ }^{22}$. En la iglesia

\footnotetext{
21 Ángeles que en este caso rodean una imagen escultórica de la Virgen María, realizada por José Luis Sánchez, y que contó con una dura oposición por el cardenal primado, hasta el punto que hubo de retirarse la pieza para bendecir la iglesia. Ver Antolín, 1983: 103.

22 Siguiendo esa fuente, el catálogo razonado del artista repite el dato.
} 
nunca estuvieron dichos cuadros ni se ha tenido noticia de algo similar. Pero sí consta la intervención de Rivera, quien pintó con acrílico para la misma un retablo con cuatro grandes lienzos (el inferior de 1,5 x $3 \mathrm{~m}$.), que tocan dos temas principales. (Fig. 11).

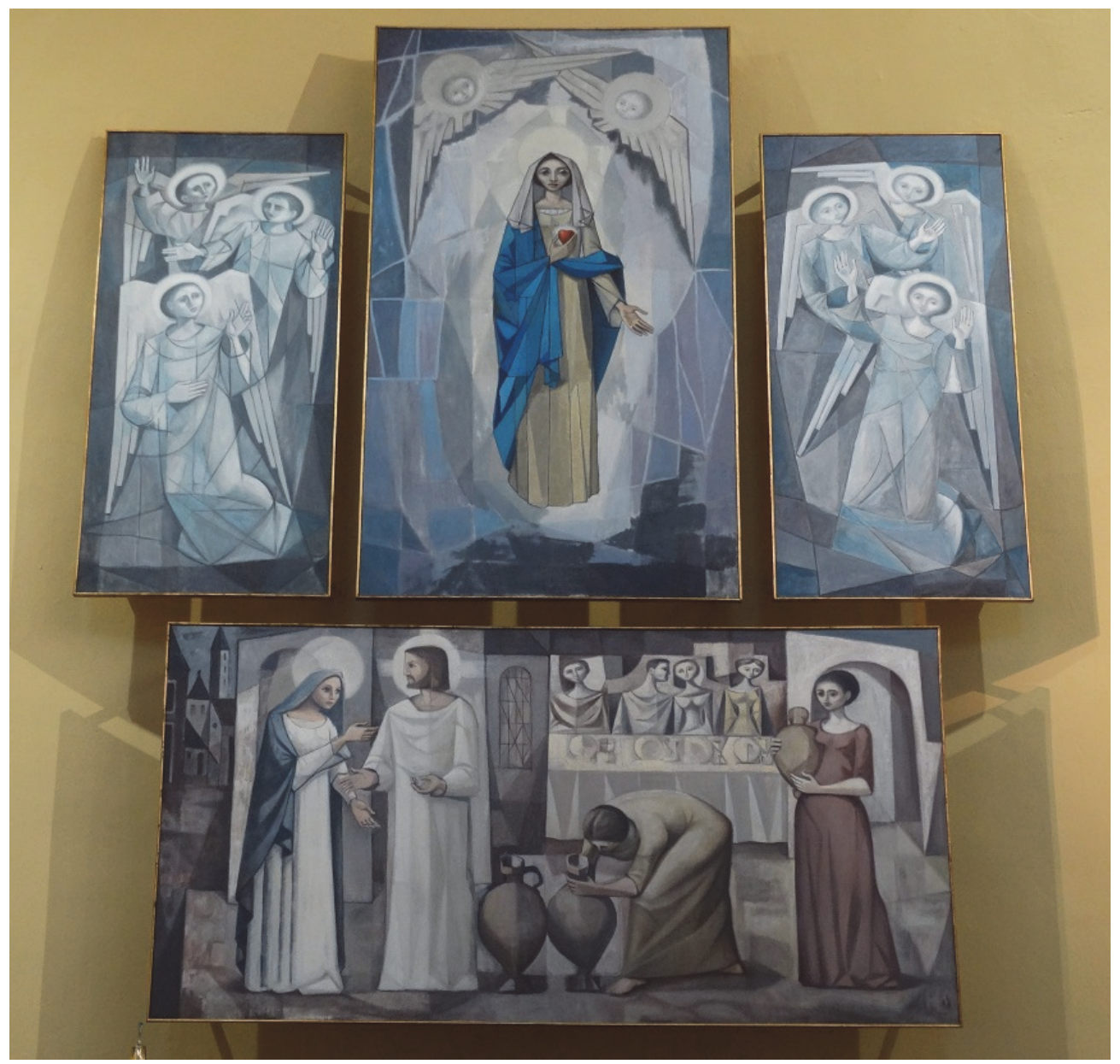

Fig. 11. Iglesia de Ruecas (Badajoz).

En el centro encontramos el Inmaculado Corazón de María, devoción vinculada con las apariciones de Fátima, aunque tuviera ya precedentes en el siglo XVII. En este caso la Virgen no muestra o señala a su corazón, sino que literalmente lo sujeta con la mano. El rostro acentúa hasta el límite las faccio- 
nes ovaladas y los ojos grandes que personalizan el estilo del autor en esta época. Dos querubines la flanquean ante un espacio irreal, que alterna líneas y manchas neutras con sutiles variaciones. Este fondo revela un planteamiento muy atrevido y moderno, al ser uno de los más abstractos realizados en este ciclo. Los paneles laterales muestran de forma equilibrada sendas tríadas de ángeles. Su actitud es gesticulante y el rostro circular y en algunos expresivo, aunque acusan un cierto isomorfismo. En estas zonas se apuesta por un tratamiento muy lineal y una sobria gama de grises y azules.

El retablo se completa debajo con la escena de Las Bodas de Caná, tema que procede del Evangelio de San Juan y que inicia las actuaciones milagrosas en la vida pública de Jesús. Ante la falta de vino, la Virgen pidió a su Hijo que interviniese, convirtiendo en vino seis tinajas llenas de agua. Rivera articula la escena en dos planos en profundidad. María y Jesús en diálogo se alzan a la izquierda, mientras dos sirvientas traen los recipientes en los que se opera el milagro. Al fondo, y enmarcados por distintas arquitecturas, la disposición de los invitados sentados a la mesa (sin escorzo en la misma), recuerda al fresco de Giotto con el mismo tema en la Capilla Scrovegni de Padua, ubicando incluso un vano en arco a la derecha. Con todo, la obra se resuelve de manera original, con las figuras de Cristo y María en pie, y un armónico equilibrio en todos los elementos.

La reciente restauración de los lienzos en 2014 por Javier Martín-Romo ha refrescado el color y aplicado protección respetando el original y va a permitir que se conserven en el tiempo sin haber alterado los trazos del autor.

Al sur del río Guadiana se encuentran los pueblos vecinos de San Francisco y San Rafael de Olivenza, diseñados por Manuel Jiménez Varea en 1954 y para los que Rivera pintó hacia 1956 los cuadros que presiden sus presbiterios. (Fig. 12).

En San Francisco, las escenas que Rivera recoge forman parte de la iconografía tradicional del Santo, inspiradas por la Vida Primera y Segunda de Tomás de Celano y la Leyenda Mayor de San Buenaventura (Guerra, 1998), escritas en el siglo XIII y base para la enorme difusión hagiográfica posterior.

El retablo sigue un esquema representativo propio de ilustraciones de la Edad Media, en las que diversos episodios se disponen alrededor de la ima- 
gen central del santo. En la tabla vertical San Francisco aparece como Alter Christus, mostrando los estigmas grabados en manos, pies y costado. Viste el hábito franciscano, luce tonsura y nimbo, y sujeta los Evangelios o el Libro de Reglas en forma de rollo. Su peculiaridad es que las llagas se presentan aureoladas con rayos de luz, en una fórmula muy poco usual.

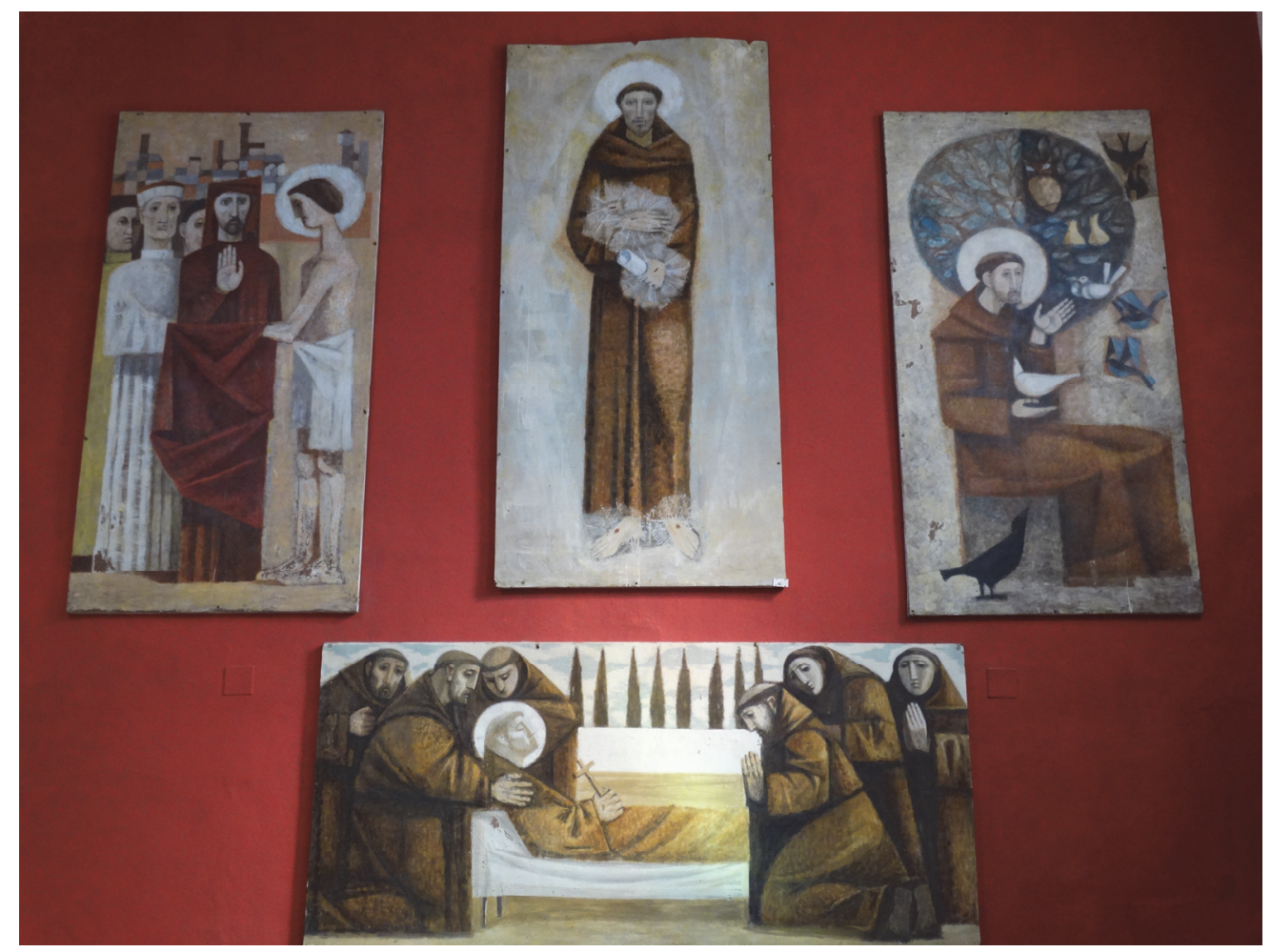

Fig. 12. Iglesia de San Francisco de Olivenza (Badajoz).

Una reciente intervención en la iglesia, aparte de pintar de un efectista rojo la pared del presbiterio, cambió la disposición de las escenas laterales. Ahora el feligrés puede leer los episodios cronológicamente a los hechos, pero no fueron concebidos así, como revela una fotografía del montaje original conservada en el Centro de Estudios Agrarios de Mérida. En la idea de Rivera primaba el criterio compositivo, cerrando visualmente el conjunto al situar a la izquierda la Predicación a los pájaros. El tema, que aparece ya en la tabla de Bonaventura Berlinghieri de 1235 y en los frescos de Giotto en 
Asís, recoge la parada del santo en Bevagna para comunicarse con las aves y exhortarlas a ensalzar al Creador; éstas, a su alrededor, alargaban el cuello, batían las alas y abrían los picos. Rivera muestra un San Francisco ingenuista, un tanto inexpresivo y con el habitual plisado en las telas; está sentado sobre una piedra y con un árbol de copa circular como fondo. Reconocemos una paloma en su mano, un cuervo a los pies, una lechuza en el árbol, golondrinas y otras especies, resultando llamativos los pájaros azules que ante el santo pliegan sus alas.

El lado opuesto rememora la renuncia de Francisco a los bienes terrenales. El santo decidió vender parte del patrimonio de su padre, y reprendido por éste fue presentado ante la autoridad eclesial. Francisco no sólo no accedió a devolverlos, sino que se despojó de sus vestiduras ante los jueces, proclamando a Dios como su verdadero Padre. Rivera tiene en cuenta el fresco de Giotto en Asís para la vestimenta y tocados de las autoridades, aunque se muestren de forma sintética. También la esquematización domina las arquitecturas del fondo, dispuestas como un mosaico similar a los que en la época realizaba su amigo el pintor José Vento, también asiduo colaborador con el Instituto Nacional de Colonización.

Cierra el conjunto la muerte de San Francisco en la Porciúncula, rodeado por sus hermanos de la orden. El santo está tendido en el lecho, sosteniendo la cruz y con el rostro iluminado por el nimbo. Con una manifiesta horizontalidad, la escena se ubica ante el muro de un cementerio sobre el que se alzan cipreses, y se circunscribe al mundo terrenal, prescindiendo de ángeles y la idea del tránsito. Los dos grupos de tres monjes arrodillados conforman una estructura equilibrada, definida además por los rostros tristes y resignados, con una peculiar fisonomía.

Las pinturas estaban fijadas a la pared por finos hierros, cuyos huecos se conservan en la superficie. Son tablas de aglomerado, combadas por el paso del tiempo y la humedad, y para intentar evitarlo en la parroquia han dispuesto tornillos en sus extremos. Pero no es suficiente; el proceso continúa y la adherencia del pigmento es muy escasa, desprendiéndose con facilidad, por lo que hay pequeñas zonas ya perdidas. Debido a ello es precisa una restauración que frene el deterioro y recupere las pinturas. 
Para la pequeña iglesia de San Rafael de Olivenza, Manuel Rivera concibió tres grandes cuadros verticales sobre aglomerado ${ }^{23}$ (Fig. 13). Domina el centro del tríptico el arcángel San Rafael, portando el bastón de peregrino y la calabaza, además del pez con el que suele asociarse su iconografía, debido a su intermediación en el conocido episodio de Tobías. Precisamente esta referencia es la que se completa en las escenas laterales. En un lado Tobías aparece junto al pez que quiso tragarle y que finalmente fue sometido, utilizando su hiel para curar la ceguera de su padre. Este momento es el que se sugiere en el panel opuesto, con las figuras unidas de padre e hijo nuevamente bajo la presencia y protección del arcángel. La factura del retablo, en una gama de colores fríos, está dominada por la linealidad y una patente segmentación de las túnicas y sobre todo las alas, en este caso con un especial dinamismo de curvas y contracurvas.

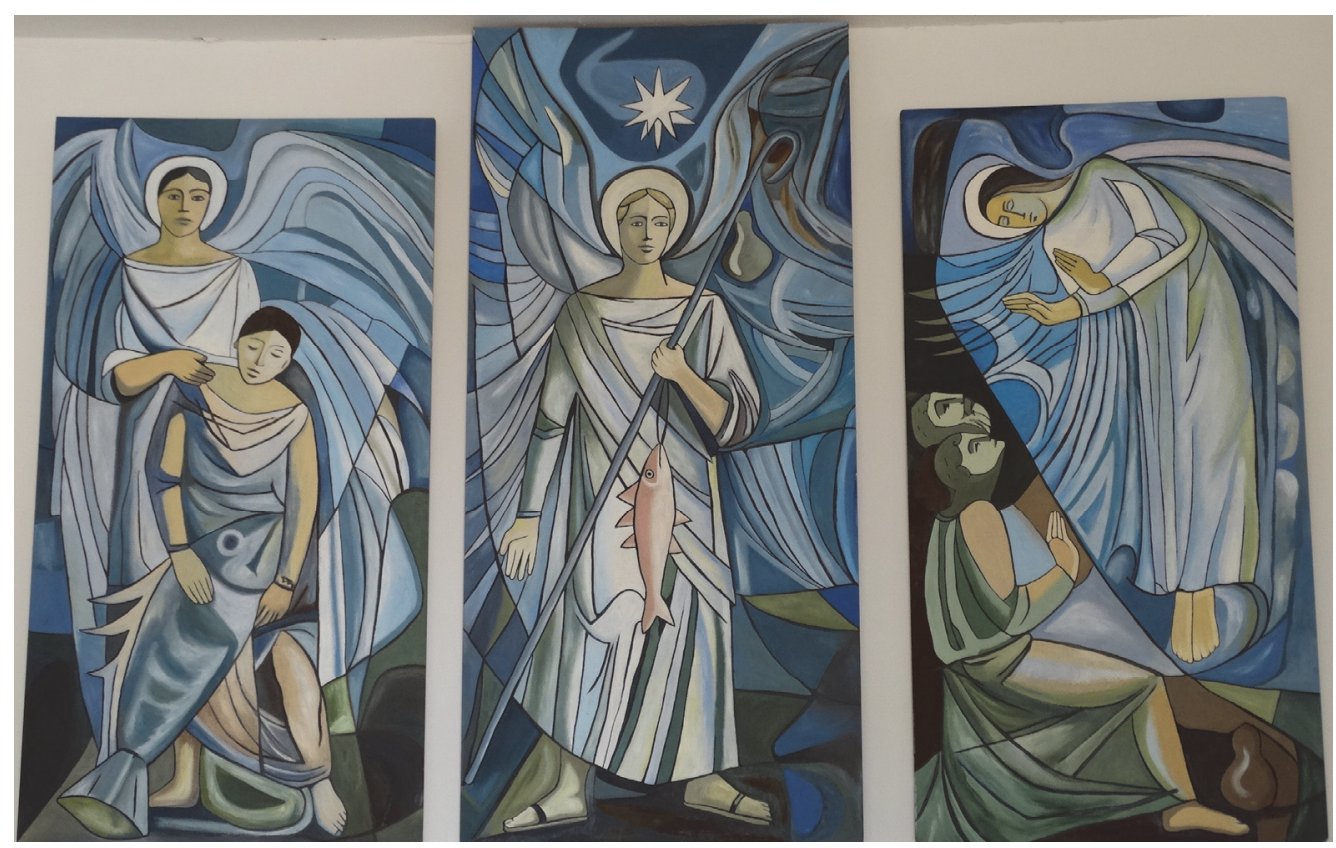

Fig. 13. Iglesia de San Rafael de Olivenza (Badajoz).

\footnotetext{
${ }^{23}$ Cada panel mide $120 \mathrm{~cm}$ de ancho, y las alturas son de 230 y $260 \mathrm{~cm}$. Las medidas coinciden con las de San Francisco.
} 
En 2004 el retablo se encontraba en un lamentable estado, que hemos podido comprobar a partir de fotografías y hacía peligrar su pervivencia. A causa de la humedad había perdido pigmentación de forma generalizada. La restauración de la obra, costeada en los materiales por la Asociación de Vecinos de San Rafael de Olivenza y autorizada por el párroco, fue encargada a María Belén Rastrollo, Licenciada en Bellas Artes y residente en el pueblo, con la colaboración de tres alumnas locales. Al comprobar que del aglomerado se desprendían virutas de madera que harían saltar el resto, se optó por lijar amplias zonas dañadas y volver a pintar sobre ellas al óleo, siguiendo las líneas y manchas del original, fijando con barniz la operación. El proceso, bienintencionado aunque poco afortunado, permite que la obra se conserve en la parroquia y cumpla su función, pero también conllevó la alteración del trazo, el sombreado y los matices de la obra riveriana ${ }^{24}$.

Dos libramientos de pago en la documentación de Rivera con fecha 3 de junio de 1957 certifican sendas obras realizadas para Extremadura: una pintura mural y un cuadro, aunque no se especifica si su realización fue inmediata o anterior en el tiempo. La primera es el mural para la parroquia de Cristo Rey de Pueblonuevo del Guadiana, fijada en 25.000 pesetas $^{25}$. (Fig. 14)

Con él asistimos a una nueva versión de la Asunción de María, pero a diferencia de Alberche ahora se prescinde de los apóstoles. Iconográficamente la obra remite al tema de la Asunción, definido como dogma por Pío XII en 1950, pero en la práctica se trata de una Ascensión, por cuanto la Virgen no es elevada, sino que sube por sí misma. La composición, rematada en arco, es cerrada y concéntrica, con el grupo de ángeles alrededor de la Virgen. El peso visual se compensa de forma equilibrada, a pesar del desigual número de personajes a un lado y otro; pero el catálogo de posiciones es muy variado, alternando la frontalidad, los tres cuartos y el perfil. Como es usual, las alas cobran un especial protagonismo, acentuado aquí por un mayor detalle en la ejecución. Toda la escena se desarrolla en el cielo, con una gama cromática

\footnotetext{
${ }^{24}$ Una segunda versión del tríptico se encuentra en Aragón, en la iglesia de El Bayo, y la está estudiando José María Alagón Laste, a quien agradezco la información. Fue instalada en 1959 e iconográficamente es idéntica, aunque su tratamiento es menos lineal y más sombreado y naturalista.

${ }^{25}$ MNCARS. Arch. RIV 3, 1-20. Según fuentes del pueblo, podría haberse llevado a cabo en torno a 1953-54, aunque la fecha del libramiento parece sugerir una datación posterior.
} 
azul, grisácea y fría, aunque con muchos matices, y delimitándose la zona de tierra en una franja inferior horizontal y estrecha, dominada en este caso por colores cálidos.

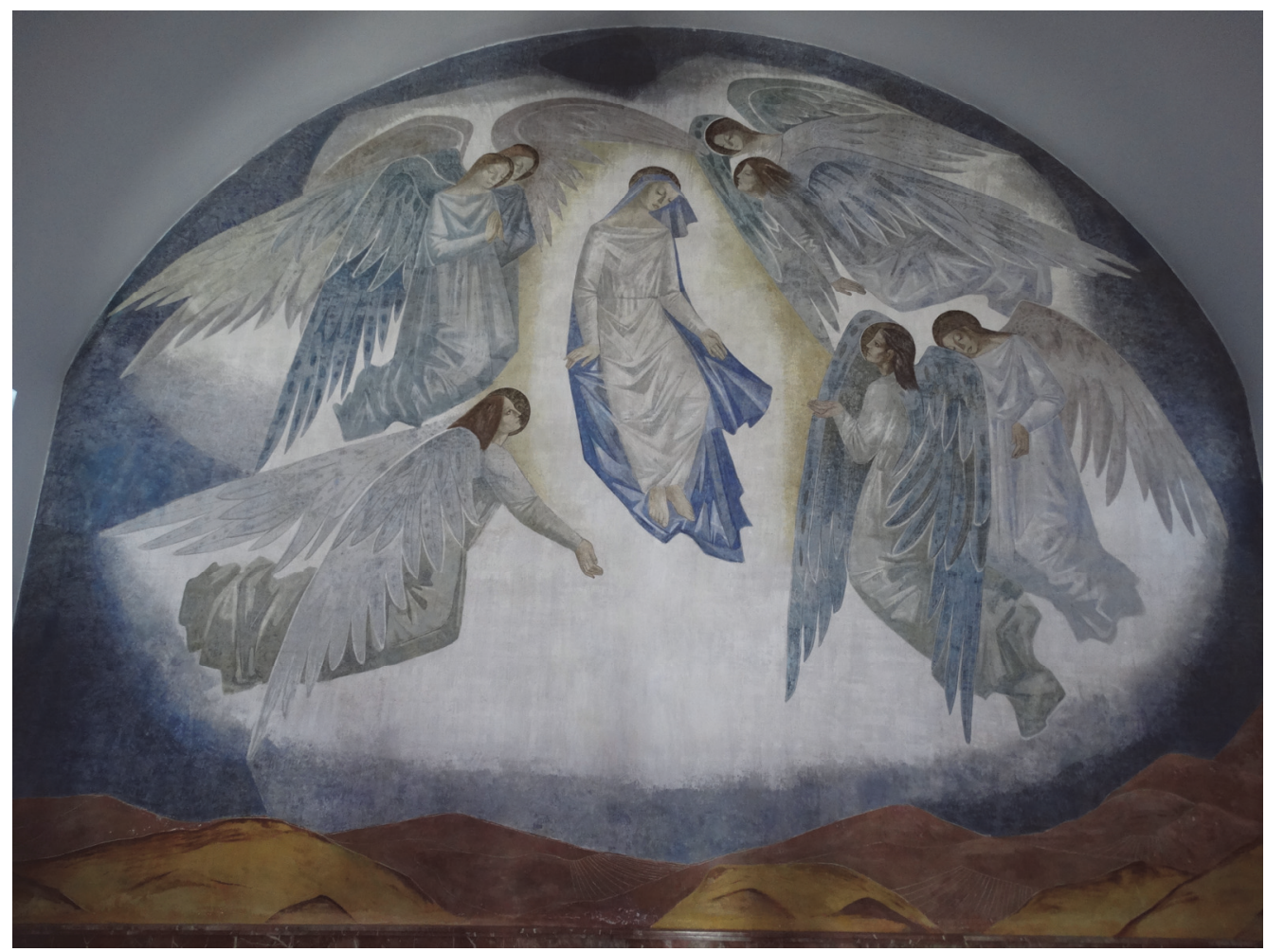

Fig. 14. Iglesia de Pueblonuevo del Guadiana (Badajoz).

Esta franja estaría en sus inicios parcialmente oculta, pues el altar se encontraba más pegado al muro, separándose por la aplicación normativa del Concilio Vaticano $\mathrm{II}^{26}$. El mural, de $5 \times 7$ metros, fue restaurado en 2013 con adecuados criterios de diferenciación y reversibilidad. Hemos tenido acceso a la memoria de intervención realizada por Fátima Merchán García. Su técnica es temple a la cola de conejo y, como en el caso de Benagéber, el principal daño era la gran pulverulencia de la capa de color, por una mala elección del aglutinante, aunado a los problemas de humedad. En consecuencia la pigmenta-

${ }^{26}$ Así lo atestiguan fotografías custodiadas en el Archivo del Centro de Estudios Agrarios de Mérida. 
ción había tenido pérdidas y se habían producido lagunas parciales. El dibujo con grafito subyace en la pintura, sobre todo en los rostros y alas, aunque además en ciertas zonas se combina con incisiones en la propia pared. El mural tuvo ya una primera intervención con pintura acrílica en 1993, coincidiendo con la restauración de la iglesia por graves problemas de humedad; se centró entonces en la parte inferior. Ahora se ha procedido a fijar y consolidar por capas las distintas zonas, evitándose ya el riesgo de desprendimiento. También se han reintegrado con acuarela las secciones más dañadas, aplicando por medio de finas líneas paralelas la técnica del rigattino. Todo ello facilita su correcta percepción actual y su futura pervivencia ${ }^{27}$.

Por último, hay constancia documental de la realización de un cuadro al óleo con el tema de San Francisco de Asís para la Capilla Escuela de La Bazana (junto a Jerez de los Caballeros, Badajoz) ${ }^{28}$, pero lamentablemente damos la obra por desaparecida. El edificio fue diseñado por Alejandro de la Sota, y estuvo en funcionamiento durante 10 o 15 años (Cabecera, 2015: 283-285 y 317). El abandono del inmueble conllevó la pérdida de la obra, que no pasó a la iglesia, y las indagaciones en la población no han dado ningún resultado. Cabe suponer que su planteamiento formal sería similar a San Francisco de Olivenza.

El final de este recorrido se enmarca en un proceso de búsqueda personal. Rivera intenta encontrarse y en sus Memorias son continuas las alusiones a los cuadros abstraizantes que inicia y abandona ante lo insatisfactorio del resultado o por la inmediatez de los encargos, que le impiden avanzar en sus investigaciones. Ello influye en que el término de esta etapa sea visto por el artista como una liberación. Sobre todo porque el encuentro con la tela metálica en 1956 sí que lo percibe como un paso definitivo hacia la consecución de un lenguaje propio, en el que quiere afianzarse. Una segunda fase de murales para la Universidad Popular de Córdoba, por casi un millón de pesetas, le hubiera otorgado una estabilidad económica notable, pero confiesa no estar ya ilusionado con este campo, al conocer los resultados de

\footnotetext{
${ }^{27}$ Llamativo es el comentario sobre que el autor frecuentaba la taberna, que, sin saber de quién se trata, recoge López, 2001: 254.

${ }^{28}$ Como hemos apuntado, en el Archivo Rivera se conserva la carta de pago del INC con el libramiento por importe de 8.500 pesetas, fechada el 3 de junio de 1957. MNCARS. Arch. RIV 3, $1-19$.
} 
antemano; de ahí que decida renunciar al encargo y regresar a Madrid para seguir explorando su prometedor hallazgo.

El desarrollo de este nuevo y personal proceso creativo con la tela metálica; la fundación y éxitos del Grupo El Paso y el rotundo triunfo en la Bienal de Venecia de 1958, abren ya una nueva etapa que consagraría su trayectoria internacional. Pero esa es otra historia, y ya bien conocida.

\section{Bibliografía.}

ARChivo Manuel Rivera. Museo Nacional Centro de Arte Reina Sofía. MNCARS. Arch. RIV 1, 2 y 3. CDB. 187199, R. 187421.

ANTOLÍN, Enriqueta (1983, 4/IV): “Artistas infiltrados. Rojos, ateos y abstractos en los pueblos de Franco", Cambio 16, Madrid, no 592, pp. 98-103.

ARÓstegui, Antonio (como Xavier Montes) (1953, 18/I): “Manuel Rivera, un joven pintor granadino en constante alza". Granada, Patria.

ARÓSTEGUI, Antonio (como XYR) (1957, 30/VI): "El autor y su obra. Manuel Rivera, un pintor granadino que triunfa en Madrid". Granada, Patria.

ARÓSTEGUI, Antonio (como XYR) (1957, 10/XI): "El autor y su obra. Manuel Rivera, éxito en la Bienal de Sao Paulo". Granada, Patria.

BAZÁN DE HuerTA, Moisés y CENTELlas SOler, Miguel (2012): “Arte religioso en los pueblos de colonización del Valle del Alagón", en LOZANO BARTOLOZZI, María del Mar y MÉNDEZ HERnÁN, Vicente (Coords.): Paisajes modelados por el agua: entre el arte y la ingeniería. Editora Regional de Extremadura, Mérida, pp. 393-421.

BAZÁn de Huerta, Moisés y Lozano Bartolozzi, María del Mar (2015): “El Agro Pontino italiano y los pueblos de colonización en la provincia de Cáceres". BSAA Arte, Valladolid, no 81, pp. 203-230.

CABECERA SORIANO, Rubén (2015): Los pueblos de colonización extremeños de Alejandro de la Sota. Editora Regional de Extremadura, Mérida, pp. 283-285 y 317.

CARDONA ANDÚJAR, José (2006): Alberche, Historia de un pueblo (1957-2007), Ayuntamiento, Alberche del Caudillo, p. 409.

CENTEllas SOlER, Miguel (2010): Los pueblos de colonización de Fernández del Amo. Fundación Caja de Arquitectos Barcelona. 
Centellas SOler, Miguel (2007) “La influencia de Fernández del Amo en el arte de las iglesias de colonización", en Pueblos de Colonización I. Fundación Arquitectura Contemporánea, Madrid.

CORDERO AMPUERO, Ángel (2014): Fernández del Amo: aportaciones al arte y la arquitectura contemporáneas. Universidad Politécnica, Madrid. (PDF descargable en http://oa.upm.es/30980/ )

De la TORRE, Alfonso y RIVERA, Marisa (2009): Manuel Rivera. Catálogo razonado de pinturas. 1943-1994. Fundación Azcona y Diputación de Granada, Granada.

DE LA TORRE, Alfonso (2012): Manuel Rivera. De Granada a Nueva York, 19461960. Centro José Guerrero, Granada.

GonzÁlez Robles, Luis (1959): Rivera. Cuadernos de Arte del Ateneo, Madrid.

GuERRA, José Antonio O.F.M. (1998): San Francisco de Asís. Escritos. Biografías. Documentos de la época. Biblioteca de Autores Cristianos, Madrid (7ª Ed).

LOGROÑO, Miguel (1981): “Los dos lados del espejo”, en 1956-1981. Manuel Rivera. Ministerio de Cultura, Madrid.

LÓPEZ LÓPEZ, Teodoro Agustín (2001): “Las parroquias pacenses del Plan Badajoz". Separata de los XXVII Coloquios Históricos de Extremadura, Fasc. 6, pp. 237-287.

MONTOYA AlONSO, Carlos (2005): La pintura mural religiosa en el Madrid del siglo XX. Universidad Complutense, Madrid. (PDF descargable en http://eprints.ucm.es/7250/)

MuÑOZ, Juan Tomás (2008, 10/II): “La iglesia de Águeda y el mural de Rivera". Salamanca, El Adelanto de Salamanca.

POPOVICI, Cirilo L. (1957, 13/X): “Arte. Españoles en la Bienal de Sao Paulo. Manuel Rivera". Madrid, S.P.

POPOVICI, Cirilo (1971): Manuel Rivera. Ministerio de Educación y Ciencia, Madrid.

RIVERA, Manuel (2007): Memorias 1928-1971. Diputación Provincial-Los libros de la Estrella 30, Granada.

TAMÉS ALARCÓN, José (1956, 10): “El arte y la arquitectura moderna” y “Edificio social del Instituto Nacional de Colonización en Madrid". Revista Na- 
cional de Arquitectura. Madrid, Colegio Oficial de Arquitectos de Madrid, $\mathrm{n}^{\mathrm{o}}$ 178 octubre, pp. 1-16.

UREÑA, Gabriel (1982): Las vanguardias artísticas en la postguerra española. 19401959. Istmo, Madrid.

VV. AA. (1992): La Universidad Politécnica restaura en San Antonio de Benagéber, Mac Center-Caja de Ahorros del Mediterráneo, Valencia.

VV. AA. (2010): Pueblos de colonización en Extremadura. Consejería de Agricultura y Desarrollo Rural de la Junta de Extremadura, Mérida.

\section{Páginas Web.}

http://manuelrivera.net/. Consultado el 1 de septiembre de 2015.

http://parroquiasanantonioabad-sab.org/historia-del-cristo-del-altar/. Consultado el 1 de septiembre de 2015. 